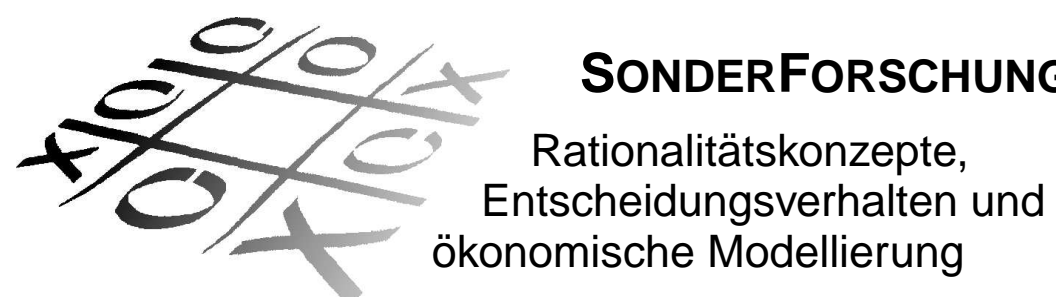

No. $04-48$

\title{
Preference for Diversification with Similarity Considerations
}

Ani Guerdjikova*

November 2004

I am indebted to my advisor Juergen Eichberger for his helpful guidance and to Alexander Zimper for his helpful suggestions and illuminating discussions. I would like to thank Hans Haller, Clemens Puppe, Itzhak Gilboa, Hans Gersbach, Klaus Ritzberger, as well as the participants of the RUD conference in Evanston, of the FUR XI conference in Paris and of the PhD seminar at the University of Heidelberg for helpful discussions and comments. Financial support from the DFG is greatfully acknowledged.

*Cornell University, email: ag334@cornell.edu

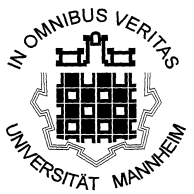

Universität Mannheim

L 13,15

68131 Mannheim 


\title{
Preference for Diversification with Similarity Considerations ${ }^{1}$
}

\author{
Ani Guerdjikova²
}

November 2004

The paper studies the connection between the form of the similarity function of a decision-maker and his willingness to diversify. It is shown that preference for diversification obtain for both high and low aspiration levels if the similarity function is convex in the Euclidean distance. However, a decision-maker with a concave similarity function and relatively high aspiration level will fail to choose diversified acts, even if his utility function is concave.

Keywords: Case-Based Decision Theory, similarity, preference for diversification JEL classification: D81, D83

\footnotetext{
$1 \quad$ I am indebted to my advisor Juergen Eichberger for his helpful guidance and to Alexander Zimper for his helpful suggestions and illuminating discussions. I would like to thank Hans Haller, Clemens Puppe, Itzhak Gilboa, Hans Gersbach, Klaus Ritzberger, as well as the participants of the RUD conference in Evanston, of the FUR XI conference in Paris and of the $\mathrm{PhD}$ seminar at the University of Heidelberg for helpful discussions and comments. Financial support from the DFG is greatfully acknowledged.

2 Cornell University, Department of Economics, Uris Hall 462, Ithaca, NY 14853, Tel.: 607255 4867, e-mail: ag334@cornell.edu.
} 


\section{Introduction}

The case-based decision theory has been proposed by Gilboa and Schmeidler $(1995,1997,2001)$ as an alternative theory for decision making under uncertainty. Differently from the expected utility theory, it models decisions in situations of structural ignorance, in which neither states of the world, nor their probabilities can be naturally derived from the description of the problem. It is assumed that a decision-maker can only learn from experience, by evaluating an act based on its own past performance and on the performance of acts similar to it. Hence, the notion of similarity plays an essential role in the case-based decision theory.

Nevertheless, the implications of the form of the similarity function for decision-making have remained by large unstudied in the literature. The application of the case-based decision theory to a specific economic environment necessitates a specification of a similarity function. However, since similarity is a relatively new concept in economic theory, there seems to be little intuition about the "right" assumptions to be imposed on the similarity function. Obviously, the acceptance of these assumptions is going to be influenced by the effects they produce on economic behavior. Hence, the question of the relationship between the similarity function and the decisions made is of importance.

In this paper, I address one part of this question: how does the form of the similarity function influence the willingness of decision-makers to diversify? I define preference for diversification as in Dekel (1989) and Chateauneuf and Tallon (2002). A decision-maker exhibits preference for diversification, if, whenever he is indifferent between two acts, he weakly prefers any linear combination of these two acts to each of them. Since a case-based decision-maker has very little information about the decision problem he is facing, his initial decisions might be due to chance. Hence, his preferences if elicited in the initial periods might vary significantly. To avoid this initial randomness, I use the limit evaluation of acts after the same decision has been repeated for a long period of time to define the preferences of the decision-maker. It is with respect to these limit preferences that preference for diversification is defined.

The findings of the paper show that the willingness to diversify depends on two factors: the height of the aspiration level and the curvature of the similarity function, but not on the curvature of the utility function. Especially, a decision-maker with a relatively low aspiration level 
will express preference for diversification independently of the form of his similarity function. However, if the aspiration level is chosen sufficiently high, preference for diversification only obtain if the similarity function is convex.

A convex similarity function implies that the greater the distance of two acts from the referential act, the less is the decision-maker able to distinguish between these two acts with respect to their similarity to the referential one. If we are ready to assume this property, then preference for diversification will obtain independently of the aspiration level of the decision-maker. Billot, Gilboa and Schmeidler (2004) have recently provided an axiomatization of a case-based rule that uses an exponential similarity function to model similarity between acts situated on the real line. However, their model does not provide an intuition of why the exponential relation might be a sensible one. This paper provides a support for the usage of an exponential similarity function. Indeed, if willingness to diversify seems to be an appealing behavioral property, then a convex similarity function would insure that this property holds in a model with case-based decision-makers.

The rest of the paper is structured as follows: in section 2, I present the model, which is similar to the model of Gilboa and Schmeidler (1996). In section 3, I discuss preference for diversification when the similarity function is convex, whereas section 4 deals with the case of a concave similarity function. Section 5 discusses some related results from the literature and concludes. The proofs of all results are stated in the appendix.

\section{The Model}

I use a version of the model of Gilboa and Schmeidler (1996). A decision-maker faces an identical decision problem $p$ in each period $t=1,2 \ldots . A \equiv[0 ; 1]^{K}$ with $K \in \mathbb{N}$ denotes the set of available acts. One can think about the corner acts (the unit vectors of the $K$-dimensional simplex) as of projects with unknown probability distribution of returns, into which a decisionmaker would like to invest his initial endowment of one unit. The simplex $A$ then represents all possible allocations of his endowment among the projects available. Let $\delta^{1} \ldots \delta^{K}$ denote the random payoffs of the corner acts and suppose that for all $i=1 \ldots K$, the distribution of $\delta^{i}$ is continuous and i.i.d. over time (although $\delta^{i}$ and $\delta^{j}$ might be correlated) with finite expectation, finite variance and bounded support. Obviously, the payoff of any act in the simplex can be 
expressed as a linear combination of $\delta^{1} \ldots \delta^{K}$.

If the utility function of the decision-maker is bounded and continuous, then the utility resulting from the choice of $a \in A$ is an i.i.d. random variable $\mathfrak{U}_{a}$ with a continuous distribution function $\left(\Pi_{a}\right)_{a \in A}$. The distributions $\left(\Pi_{a}\right)_{a \in A}$ have finite expectations $\mu_{a}$, finite variance $\sigma_{a}$ and bounded and convex supports $\Delta_{a}$. $\mu_{a}$ is continuous with respect to $a$.

The decision-maker's perception of similarity is described by a function $s: A \times A \rightarrow[0 ; 1]$ :

$$
\begin{aligned}
s(a ; a) & =1 \\
s\left(a ; a^{\prime}\right) & =s\left(a^{\prime} ; a\right) \\
s\left(e^{i} ; e^{j}\right) & =0
\end{aligned}
$$

for all distinct $i$ and $j \in\{1 \ldots K\}$, where $e^{i}$ denotes the $i^{t h}$ unit vector. $s$ depends only on the Euclidean distance between $a$ and $a^{\prime}$.

The memory of the decision-maker is represented by a set of cases. A case is a triple of a problem encountered, an act chosen and a utility realization achieved. Since the problem is identical in each period of time, a case is characterized by an act and a utility realization. As in Gilboa and Schmeidler (1996), the memory $M_{t}$ contains only cases actually encountered by the decision-maker until period $t$ :

$$
M_{t}=\left(\left(a_{\tau} ; u_{\tau}\right)\right)_{\tau=1,2 \ldots t} .
$$

The aspiration level of the decision-maker in period $t$ is $\bar{u}_{t}$. In the present paper, I will assume that $\bar{u}_{t}=\bar{u}=$ const and concentrate only on the influence of $\bar{u}$ and $s$ on the willingness to diversify, thus neglecting the effect of aspiration adaptation.

The case-based decision-rule prescribes choosing the act with maximal cumulative utility in each period of time. The cumulative utility of an act $a$ at time $t$ is given by:

$$
U_{t}(a)=\sum_{\tau=1}^{t} s\left(a ; a_{\tau}\right)\left(u_{\tau}-\bar{u}\right) .
$$

The set of all possible decisions paths that can be observed can be written as

$$
S_{0}=\left\{\omega=\left(a_{t} ; u_{t} ; \bar{u}\right)_{t=1,2 \ldots} \mid a_{t} \in A, u_{t} \in \Delta\right\},
$$

where $\Delta=\cup_{a \in A} \Delta_{a}$ denotes the set of possible utility realizations. Let $S_{1}$ be the set of those paths on which the decision-maker chooses $\arg \max _{a \in A} U_{t}(a)$ in each period:

$$
S_{1}=\left\{\omega \in S_{0} \mid a_{t}=\arg \max _{a \in A} U_{t}(a) \text { for all } t=1,2 \ldots\right\} .
$$


As well as $a_{t}$ and $u_{t}$ all variables introduced below depend on the path $\omega$. I neglect this dependence in the notation for simplicity of exposition.

$C_{t}(a)$ denotes the set of periods preceding $t$ in which $a$ has been chosen:

$$
C_{t}(a)=\left\{\tau<t \mid a_{\tau}=a\right\}
$$

Let $P$ be a probability measure on $S_{1}$ consistent with $\left(\Pi_{a}\right)_{a \in A}$, as in Gilboa and Schmeidler (1996, p.11).

Denote by

$$
\pi(a)=\lim _{t \rightarrow \infty} \frac{\left|C_{t}(a)\right|}{t}
$$

the frequency with which $a$ is chosen, if the limit on the right hand side exists. In general, this frequency will be path-dependent.

Willingness to diversify is defined as in Dekel (1989) and Chateauneuf and Tallon (2002). Assume that

$$
a_{1} \sim a_{2} \sim \ldots \sim a_{n}
$$

Then a decision maker exhibits preferences for diversification if for any $\beta_{1} \ldots \beta_{n} \geq 0$ such that $\sum_{i=1}^{n} \beta_{i}=1$

$$
\sum_{i=1}^{n} \beta_{i} a_{i} \succeq a_{k} \text { for any } k=1 \ldots n .
$$

The preferences of a case-based decision-maker are captured by the cumulative utility he assigns to different acts. Clearly, these preferences will in general vary over time. Hence, to derive meaningful statements about the willingness to diversify, it seems reasonable to consider the preferences of a decision-maker in the limit as $t \rightarrow \infty$. Then, $a_{1} \sim a_{2}$ will correspond to

$$
\lim _{t \rightarrow \infty} \frac{U_{t}\left(a_{1}\right)}{U_{t}\left(a_{2}\right)}=1
$$

Preference for diversification will obtain if for all $a_{1} \ldots a_{n}$ such that

$$
\begin{gathered}
\lim _{t \rightarrow \infty} \frac{U_{t}\left(a_{k}\right)}{U_{t}\left(a_{l}\right)}=1 \text { for all } k \text { and } l \in\{1 \ldots n\} \\
\frac{\lim _{t \rightarrow \infty} U_{t}\left(\sum_{i=1}^{n} \beta_{i} a_{i}\right)}{\lim _{t \rightarrow \infty} U_{t}\left(a_{k}\right)} \geq 1
\end{gathered}
$$

if both the numerator and the denominator converge to $+\infty$ and

$$
\frac{\lim _{t \rightarrow \infty} U_{t}\left(\sum_{i=1}^{n} \beta_{i} a_{i}\right)}{\lim _{t \rightarrow \infty} U_{t}\left(a_{k}\right)} \leq 1,
$$

if the numerator and the denominator converge to $-\infty$. Note that the definition of preference for diversification depends (through $U_{t}$ ) on the chosen decision path. However, it will be shown 
that the emergence of preferences for diversification will depend only on the aspiration level and on the form of the similarity function and not on the specific path $\omega$.

\section{Preference for Diversification with a Convex Similarity Function}

Consider a decision-maker whose perception of similarity is described by

$$
s\left(a ; a^{\prime}\right)=f\left(\left\|a-a^{\prime}\right\|\right),
$$

with $f^{\prime}<0$. The matrix

$$
f^{\prime \prime} d E \cdot(d E)^{T}+d^{2} E f^{\prime}
$$

is assumed to be positive definite, where $E$ denote the Euclidean distance functional. Note that this assumption implies that for a given $a s\left(a ; a^{\prime}\right)$ is convex on any set $\hat{A} \subset A$ such that $a \notin \hat{A}$. This follows from the fact that for $a \neq a^{\prime} s\left(a ; a^{\prime}\right)$ is differentiable with:

$$
d^{2} s=f^{\prime \prime} d E \cdot(d E)^{T}+d^{2} E f^{\prime} .
$$

The similarity function $s(\cdot ; \cdot)$ is illustrated in figure 1 for the case $K=2$.

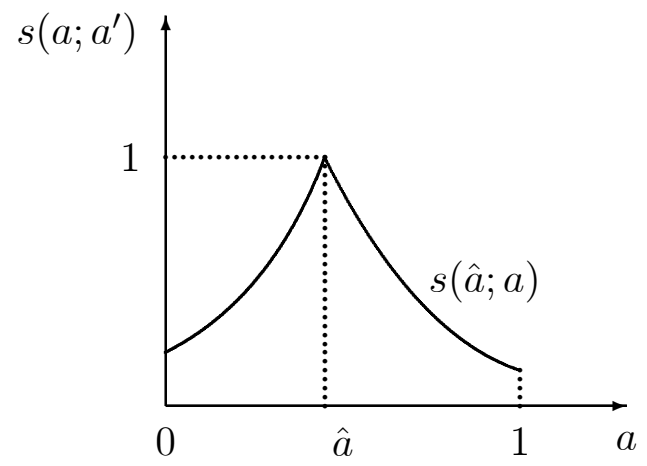

Figure 1

Note that the similarity function itself cannot be convex over the whole set $[0 ; 1]^{K}$ since it must assume a maximum at $s(a ; a)$. However, I will refer to similarity functions described above as convex.

Let $a_{1}=\bar{a}$ denote the act chosen in the first period and assume that $\bar{a} \in \operatorname{int}(A)$. $\Omega$ describes the set of possible paths:

$$
\Omega=\left\{\begin{array}{ll}
\omega \in S_{1} \mid & \begin{array}{l}
\bar{u}_{t}=\bar{u} \text { for all } t=1,2, \ldots \\
a_{1}=\bar{a}
\end{array}
\end{array}\right\} .
$$


Let $P$ denote a probability measure on $\Omega$ consistent with $\left(\Pi_{a}\right)_{a \in A}$ as in Gilboa and Schmeidler (1996, p.11).

Proposition 1 Suppose that the similarity function is convex. If the aspiration level satisfies $\mu_{a}<\bar{u}$ for all $a \in A$ then for all $a$ and $a^{\prime} \in A$

holds P-almost surely.

$$
\lim _{t \rightarrow \infty} \frac{U_{t}(a)}{U_{t}\left(a^{\prime}\right)}=1
$$

Proposition 2 Suppose that the similarity function is convex. If the aspiration level satisfies $\mu_{a}>\bar{u}$ for some $a \in A$, then $P$-almost surely an act

$$
a^{*} \in \tilde{A}=\left\{a \in A \mid \mu_{a}>\bar{u}\right\}
$$

is chosen with frequency 1 in the limit.

Obviously, if the aspiration level of the decision-maker is relatively low, he will choose a single act $a^{*}$ with frequency one in the limit. Moreover, $\mu_{a^{*}}>\bar{u}$ holds. In this case,

$$
\lim _{t \rightarrow \infty} U_{t}(a)=+\infty
$$

holds for all $a \in A$ and

$$
\begin{aligned}
& \lim _{t \rightarrow \infty} \frac{U_{t}\left(a^{*}\right)}{U_{t}\left(a_{l}\right)}=\frac{1}{s\left(a^{*} ; a_{l}\right)} \geq 1 \\
& \lim _{t \rightarrow \infty} \frac{U_{t}\left(a_{k}\right)}{U_{t}\left(a_{l}\right)}=\frac{s\left(a^{*} ; a_{k}\right)}{s\left(a^{*} ; a_{l}\right)} .
\end{aligned}
$$

If $a^{*}=e^{i}$ for some $i \in\{1 \ldots K\}$, there will be no distinct $a_{k}$ and $a_{l}$ such that

$$
\lim _{t \rightarrow \infty} \frac{U_{t}\left(a_{k}\right)}{U_{t}\left(a_{l}\right)}=1
$$

holds. Hence, the condition of preference for diversification is trivially satisfied. If, however $a^{*} \in \operatorname{int}(A)$, then

$$
s\left(a^{*} ; a_{j}\right)=s\left(a^{*} ; a_{i}\right),
$$

iff

$$
\left\|a^{*}-a_{j}\right\|=\left\|a-a_{i}\right\|
$$

Obviously, then for any $a_{1} \ldots a_{n}$ satisfying (1) for any $i, j \in\{1 \ldots n\}$,

for every $\beta_{i} \in[0 ; 1], \sum_{i=1}^{n} \beta_{i}=1$. Hence,

$$
\left\|a^{*}-a_{k}\right\| \geq\left\|a^{*}-\sum_{i=1}^{n} \beta_{i} a_{i}\right\|
$$

$$
s\left(\sum_{i=1}^{n} \beta_{i} a_{i} ; a^{*}\right) \geq s\left(a^{*} ; a_{i}\right)=s\left(a^{*} ; a_{j}\right)
$$

for all $i$ and $j \in\{1 \ldots n\}$ and, therefore $\sum_{i=1}^{n} \beta_{i} a_{i}$ is (weakly) preferred to $a_{i}$ in the limit for all 
$i=1 \ldots n:$

$$
\lim _{t \rightarrow \infty} \frac{U_{t}\left(\sum_{i=1}^{n} \beta_{i} a_{i}\right)}{U_{t}\left(a_{i}\right)}=\frac{s\left(a^{*} ; \sum_{i=1}^{n} \beta_{i} a_{i}\right)}{s\left(a^{*} ; a_{i}\right)} \geq 1 .
$$

In the case of high aspiration level (proposition 1), since all acts fulfill

preference for diversification trivially obtains.

$$
\lim _{t \rightarrow \infty} \frac{U_{t}(a)}{U_{t}\left(a^{\prime}\right)}=1
$$

The following corollary obtains:

Corollary 3 If the similarity function is convex, preference for diversification obtains independently of the aspiration level of the decision-maker.

\section{The Case of Concave Similarity Function}

\section{Assumption 1}

where $f^{\prime}<0$ and the matrix

$$
s\left(a ; a^{\prime}\right)=f\left(\left\|a-a^{\prime}\right\|\right),
$$

is negative definite.

$$
f^{\prime \prime} d E \cdot(d E)^{T}+d^{2} E f^{\prime}
$$

Note that this assumption implies that $s$ is concave.

$s$ is illustrated in figure 2 for $K=2$.

The concavity of $s$ implies that the greater the distance of two acts $a^{\prime}$ and $a^{\prime \prime}$ from the reference act $a$, the more the decision-maker distinguishes between $a^{\prime}$ and $a^{\prime \prime}$ with respect to their similarity to $a$.

The next proposition shows how a decision-maker will behave if his aspiration level is higher than the mean utility of the initially chosen act.

Proposition 4 Let the similarity function $s\left(a ; a^{\prime}\right)$ of a decision-maker be concave. If $\bar{u}>\mu_{\bar{a}}$ and

- $\bar{u}>\max \left\{\mu_{e^{1}} ; \ldots ; \mu_{e^{K}}\right\}$, then

$P\left\{\omega \in \Omega \mid \exists \pi(a):[0 ; 1]^{K} \rightarrow[0 ; 1]\right.$ and $\frac{\pi\left(e^{i}\right)}{\pi\left(e^{j}\right)}=\frac{\mu_{e^{j}}-\bar{u}}{\mu_{e^{i}}-\bar{u}}, \pi(a)=0$ for $\left.a \in \operatorname{int}(A)\right\}=1$;

- $\bar{u}>\mu_{e^{i}}$ for all $i \in K^{\prime} \subset\{1 \ldots K\}$, then

$$
P\left\{\omega \in \Omega \mid \exists \pi(a):[0 ; 1] \rightarrow[0 ; 1] \text { and } \exists i \in K^{\prime} \text { such that } \pi\left(e^{i}\right)=1\right\}=1 \text {. }
$$




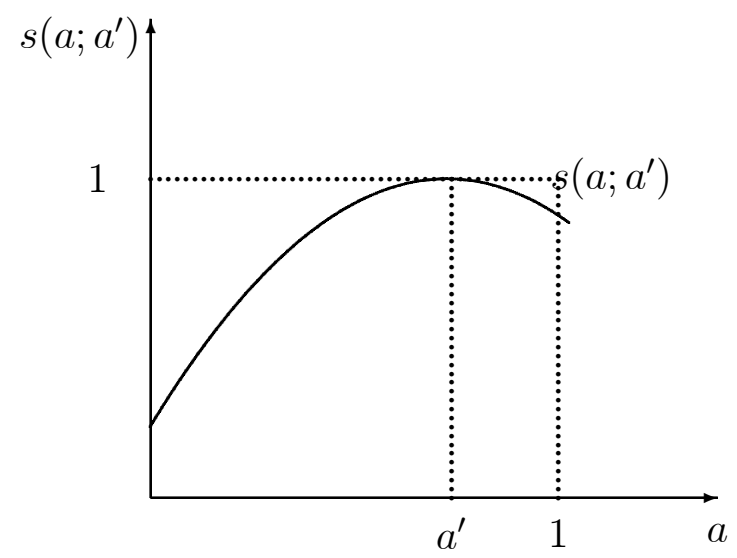

Figure 2

If the aspiration level of a decision-maker is relatively low, then the result of corollary 3 holds and preference for diversification obtains.

However, this is not the case for relatively high aspiration levels. The following corollary obtains:

Corollary 5 If the similarity function is concave, a decision-maker exhibits preference for diversification if and only if his aspiration level satisfies $\bar{u}<\mu_{a}$ for some $a \in A$.

To see that the result of the corollary indeed holds, consider the case of $\bar{u}>\max _{i \in\{1 \ldots K\}}\left\{\mu_{e^{i}}\right\}$. An examination of the proof of proposition 4 shows that in this case:

for all $i$ and $j \in\{1 \ldots K\}$ and

$$
\lim _{t \rightarrow \infty} \frac{U_{t}\left(e^{i}\right)}{U_{t}\left(e^{j}\right)}=1
$$

$$
\lim _{t \rightarrow \infty} U_{t}(a)=-\infty
$$


for all $a \in A$, whereas

$$
\lim _{t \rightarrow \infty} \frac{U_{t}(a)}{U_{t}\left(e^{i}\right)}=\lim _{t \rightarrow \infty} \frac{U_{t}(a)}{U_{t}\left(e^{i}\right)}>1
$$

for all $i \in\{1 \ldots K\}$ and all $a \in \operatorname{int}(A)$. Note, however that any interior act can be expressed as

$$
a=\sum_{i=1}^{K} \beta_{i} e^{i}
$$

for some non-negative $\beta_{i}$ with $\sum_{i=1}^{K} \beta_{i}=1$ and still the corner acts $e^{i}$ are strictly preferred to $a \in$ int $(A)$ in the limit. Hence, the decision-maker does not exhibit preference for diversification in this case. Note further that this result does not depend on the form of the utility function $u$.

\section{Conclusion}

The findings of the paper are consistent with the model of preferences for diversity proposed by Nehring and Puppe (2002, 2003). Differently from the approach of Gilboa and Schmeidler (1997), Nehring and Puppe derive a similarity function indirectly by first imposing conditions guaranteeing preference for diversity and then concluding what the similarity perceptions of a decision-maker with such a utility function might be. This approach does not, however guarantee that similarity is a complete relation. They compute the similarity function corresponding to preferences for diversity over acts situated on a one-dimensional simplex. They conclude that preference for diversity implies a similarity function which is convex in the Euclidean distance. Hence, despite the differences in the structure of the models, the implications of the curvature of the similarity function seem to be similar in both settings.

Up to now, few works have used the concept of similarity in case-based decisions. Gilboa and Schmeidler (2001, chapter 19) show that positive (negative) similarity between goods can be interpreted in terms of complementarity (substitutability). Blonski (1999) proposes to model social structures using similarity functions. The similarity describes how relevant the experience of other members of the society is for the decision-maker at hand. He shows that different equilibria emerge depending on the structure of the society. However, both papers use similarity functions on finite set of acts, whereas similarity functions defined on uncountable sets are still largely unstudied, except for Gayer (2003).

Empirical evidence about similarity perceptions in economic situations is by large missing, the few exceptions being Buschena and Zilberman (1995, 1999) and Zizzo (2002). Their findings 
show that similarity between is related to the Euclidean distance between payoffs. The present paper stresses that the exact form of the dependence on the Euclidean distance might matter at least in certain applications. It suggests that empirical research about the form of the similarity function might provide more insights about the willingness of people to diversify and might help to solve empirical puzzles related to this issue.

\section{Appendix}

I start with two lemmas which will be useful in proving the results.

Lemma 6 If $\bar{u}<\mu_{\bar{a}}$, then the expected time, during which the decision-maker will hold $\bar{a}$ is infinite. If $\bar{u}>\mu_{\bar{a}}$, then the decision-maker will almost surely switch in finite time to a corner act $e^{i}$ such that

$$
a=\max _{i \in\{1 \ldots K\}}\left\|e^{i}-\bar{a}\right\|
$$

\section{Proof of lemma 6}

Suppose first that $\bar{u}<\mu_{\bar{a}}$. The cumulative utility of $\bar{a}$, as long as the investor holds it, is then a random walk with differences

$$
\mu_{\bar{a}}-\bar{u}
$$

Since the expected value of the difference is $\mu_{\bar{a}}-\bar{u}>0$ and the process starts at 0 , the expected time until the first period in which the process reaches 0 is $\infty$. But, as long as $U_{t}(\bar{a})>0$, $U_{t}(a)=s(a ; \bar{a}) U_{t}(\bar{a}) \geq U_{t}(\bar{a})$, since $s(a ; \bar{a}) \in[0 ; 1]$ and, therefore, $\bar{a}$ is chosen.

Now suppose that $\bar{u}>\mu_{\bar{a}}$. Then, the expected increments of $U(\bar{a})$ are negative. Therefore, when the process starts at 0 , it will cross any finite barrier below 0 in finite time. Let $t$ be the first period, at which $U_{t}(\bar{a})<0$. Then $U_{t}(a)=s(a ; \bar{a}) U_{t}(\bar{a})<0$. Since $s=\left(a ; a^{\prime}\right)$ is strictly decreasing in the distance between the acts, $U_{t}(a)$ has a maximum either at one of the corner acts. It follows that

$$
a_{t+1}=\max _{i \in\{1 \ldots K\}}\left\|e^{i}-\bar{a}\right\|
$$

Lemma 7 Define $V_{t}(a)$ as:

$$
V_{t}(a)=\sum_{\tau \in C_{t}(a)}\left[u_{\tau}(a)-\bar{u}_{t}\right]
$$

An act $a$ is only abandoned in periods $\tilde{t}$ such that $V_{\tilde{t}}(a)<0$.

In lemma 6, it has already been shown that the statement of the lemma is true up to time $\bar{t}$ such 
that

$$
\bar{t}=\min \left\{t \mid U_{t}(\bar{a})<0\right\} .
$$

To argue by induction, suppose that the statement holds up to a period $t-1$ and consider period $t$. Denote by $a_{1} \ldots a_{l}$ the acts that have been chosen up to period $t$ in this order, $a_{l}=a_{t}$. Suppose that $V_{t}(a) \geq 0$. Then the cumulative utility of $a_{l}$ at $t$ can be written as:

$$
\begin{aligned}
U_{t}\left(a_{l}\right) & =\sum_{\substack{i=1 \\
i \neq l}}^{l} V_{t}\left(a_{i}\right) s\left(a_{i} ; a_{l}\right)+V_{t}\left(a_{l}\right) \geq \\
& \geq \sum_{\substack{i=1 \\
i \neq l}}^{l} V_{\bar{t}^{\prime \prime}}\left(a_{i}\right) s\left(a_{i} ; a_{l}\right)+V_{\bar{t}^{\prime \prime}}\left(a_{l}\right),
\end{aligned}
$$

where $\bar{t}^{\prime \prime}+1$ denotes the last period prior to $t$ in which the decision-maker has switched to $a_{l}$ from a different act. The inequality follows from the fact that $V_{\bar{t}^{\prime \prime}}\left(a_{l}\right) \leq 0$, since either act $a_{l}$ has been chosen for the first time at $t^{\prime \prime}$ and therefore $V_{\bar{t}^{\prime \prime}}\left(a_{l}\right)=0$ or $a_{l}$ has been abandoned for the last time at some time $t^{\prime \prime}+1<\bar{t}^{\prime \prime}+1$ and then

$$
V_{\bar{t}^{\prime \prime}}\left(a_{l}\right)=V_{t^{\prime \prime}}\left(a_{l}\right)<0
$$

must hold. Since the acts different from $a_{l}$ have not been chosen after period $\bar{t}^{\prime \prime}$,

$$
V_{\bar{t}^{\prime \prime}}\left(a_{i}\right)=V_{t}\left(a_{i}\right)
$$

holds for $i \in\{1 \ldots l-1\}$.

Furthermore, since $a_{\bar{t}^{\prime \prime}+1}=a_{l}$, it must be that for all $a \in A$ :

holds. But then

$$
U_{\bar{t}^{\prime \prime}}\left(a_{l}\right)=\sum_{\substack{i=1 \\ i \neq l}}^{l} V_{\bar{t}^{\prime \prime}}\left(a_{i}\right) s\left(a_{i} ; a_{l}\right)+V_{\bar{t}^{\prime \prime}}\left(a_{l}\right) \geq U_{\bar{t}^{\prime \prime}}(a)
$$

$$
\begin{aligned}
U_{t}\left(a_{l}\right)-U_{t}(a) & =\sum_{\substack{i=1 \\
i \neq l}}^{l} V_{t}\left(a_{i}\right)\left[s\left(a_{i} ; a_{l}\right)-s\left(a_{i} ; a\right)\right]+V_{t}\left(a_{l}\right)\left(1-s\left(a_{l} ; a\right)\right) \\
& \geq \sum_{\substack{i=1 \\
i \neq l}}^{l} V_{\bar{t}^{\prime \prime}}\left(a_{i}\right)\left[s\left(a_{i} ; a_{l}\right)-s\left(a_{i} ; a\right)\right]+V_{\bar{t}^{\prime \prime}}\left(a_{l}\right)\left(1-s\left(a_{l} ; a\right)\right) \\
& =U_{\bar{t}^{\prime \prime}}\left(a_{l}\right)-U_{\bar{t}^{\prime \prime}}(a) \geq 0 .
\end{aligned}
$$

Hence, $a_{t+1}=a_{l}$ if $V_{t}\left(a_{l}\right) \geq 0$ and hence, an act $a_{l}$ can be only abandoned in a period $\tilde{t}$ such that $V_{t}\left(a_{l}\right)<0$ holds. 


\section{Proof of proposition 1}

The proof of the proposition proceeds in two steps. First I show that each open subset of $A$ is chosen by the decision-maker for an infinite number of periods. This is an implication of the convexity of the similarity function and the negativity of net expected payoffs. Second, the negativity of net expected payoffs and the i.i.d. process of payoffs are used to demonstrate that the difference between the cumulative utilities of any two acts remains bounded in the limit. This implies the result of the proposition.

Lemma 8 There is no $x \in \operatorname{int}(A)$ such that for all acts $a \in B_{x}(\epsilon)$ (where $B_{x}(\epsilon)$ is an open ball with radius $\epsilon$ around $x \in(0 ; 1)),\left|C_{t}(a)\right|<\infty$ holds.

\section{Proof of lemma 8}

First note that no single act $a$ can be chosen with frequency one, since then for any act $a^{\prime} \neq a$, the $\mu_{a}-\bar{u}<0$ would imply:

$$
\lim _{t \rightarrow \infty}\left[U_{t}(a)-U_{t}\left(a^{\prime}\right)\right]=\lim _{t \rightarrow \infty} V_{t}(a)\left[1-s\left(a^{\prime} ; a\right)\right] \rightarrow-\infty \text { a.s. }
$$

Hence, choosing $a$ in each period of time would contradict the case-based rule.

Suppose, therefore that only two acts $a^{\prime}$ and $a^{\prime \prime}$ are chosen infinitely often. Hence, there is a time $T$ such that $a_{t} \in\left\{a^{\prime} ; a^{\prime \prime}\right\}$ for all $t>T$. Denote the acts chosen in periods $1 \ldots T$ by $a_{1} \ldots a_{l}$. The cumulative utility of act $a$ at $t>T$ is given by:

$$
U_{t}(a)=V_{t}\left(a^{\prime}\right) s\left(a ; a^{\prime}\right)+V_{t}\left(a^{\prime \prime}\right) s\left(a ; a^{\prime \prime}\right)+\sum_{i=1}^{l} V_{t}\left(a_{i}\right) s\left(a ; a_{i}\right) .
$$

By lemma 7, a decision-maker will only switch away from an act $a$ if $V_{t}(a)<0$. Hence, $V_{t}\left(a_{i}\right)<0$ holds for all $i=1 \ldots l$. Whereas $V_{t}\left(a_{i}\right)$ are finite for all $i=1 \ldots l, V_{t}\left(a^{\prime}\right)$ and $V_{t}\left(a^{\prime \prime}\right)$ a.s. tend to $-\infty$, i.e. for almost each $\omega$ there exists some time $t(\omega)$ such that $V_{t}\left(a^{\prime}\right)$ and $V_{t}\left(a^{\prime \prime}\right)$ are negative for all $t \geq t(\omega)$.

Since the similarity function is convex, it follows that $U_{t}(a)$ is strictly concave on the intervals:

as well as on

$$
\begin{aligned}
& \left(a^{\prime} ; \min \left\{\min _{i \in\{1 \ldots l\}}\left\{a_{i} \mid a_{i}>a^{\prime}\right\} ; a^{\prime \prime}\right\}\right) \\
& \left(\max \left\{0 ; \max _{i \in\{1 \ldots l\}}\left\{a_{i} \mid a_{i}<a^{\prime}\right\}\right\} ; a^{\prime}\right),
\end{aligned}
$$

$$
\left(a^{\prime \prime} ; \min \left\{\min _{i \in\{1 \ldots T\}}\left\{a_{i} \mid a_{i}>a^{\prime \prime}\right\} ; 1\right\}\right)
$$




$$
\left(\max \left\{a^{\prime} ; \max _{i \in\{1 \ldots T\}}\left\{a_{i} \mid a_{i}<a^{\prime \prime}\right\}\right\} ; a^{\prime \prime}\right) .
$$

Hence, on almost each path, there exists a period of time $T^{\prime}(\omega)$ such that there exist acts $a^{\prime \prime \prime}$ and $a^{\prime v}$ such that

$$
\begin{aligned}
& U_{t}\left(a^{\prime \prime \prime}\right)>U_{t}\left(a^{\prime}\right) \\
& U_{t}\left(a^{\prime v}\right)>U_{t}\left(a^{\prime \prime}\right)
\end{aligned}
$$

for all $t \geq T^{\prime}(\omega)$ and still $a_{t} \in\left\{a^{\prime} ; a^{\prime \prime}\right\}$ is chosen. This obviously contradicts the case-based rule. Clearly, the argument does not depend on the number of acts which are chosen infinitely often, as long as this number remains finite. Hence, an infinite (but countable) set of acts $A^{\prime}$ must be chosen infinitely often.

Suppose now that $A^{\prime}$ does not contain an act out of $B_{x}(\epsilon)$ for some $x \in \operatorname{int}(A)$. By an argument similar to the above, we could find an element of $B_{x}(\epsilon), \tilde{a}$ which has been chosen only for a finite number of times and show that from some point of time $T^{\prime \prime}(\omega)$, the cumulative utility of the acts in the interval

$$
\left(\sup A^{\prime} \backslash[x+\epsilon ; 1] ; \tilde{a}\right)
$$

is a concave function for all $t \geq T^{\prime \prime}(\omega)$. Hence, for all

$$
\begin{gathered}
a \in\left(\sup A^{\prime} \backslash[x+\epsilon ; 1] ; \tilde{a}\right) \\
U_{t}(a)>U_{t}\left(\sup A^{\prime} \backslash[x+\epsilon ; 1]\right) .
\end{gathered}
$$

By the continuity of the cumulative utility function, there exists an act $a^{\prime} \in A^{\prime}$ which is chosen infinitely often and the cumulative utility of which lies below the cumulative utility of $a$ in each period $t \geq T^{\prime \prime}(\omega)$, a contradiction.

Remark 1 A similar argument can be used to show that every corner act in the simplex will be chosen infinitely often.

To complete the proof of the proposition, I now show that the difference between the cumulative utilities of any two acts:

$$
U_{t}(a)-U_{t}\left(a^{\prime}\right)=: \varepsilon_{t}\left(a ; a^{\prime}\right)
$$

a.s. remains bounded over time. Since the expected mean payoffs of all acts are negative,

$$
\lim _{t \rightarrow \infty} U_{t}(a)=-\infty
$$

a.s. for all acts $a \in A$. This implies that

$$
\lim _{t \rightarrow \infty} \frac{U_{t}(a)}{U_{t}\left(a^{\prime}\right)}=\lim _{t \rightarrow \infty} \frac{U_{t}(a)}{U_{t}(a)+\varepsilon_{t}\left(a ; a^{\prime}\right)}=1
$$


holds on all paths on which $\varepsilon_{t}\left(a ; a^{\prime}\right)$ remains bounded.

Hence, the proof of the following lemma would complete the proof of proposition 1:

Lemma 9 Define $\varepsilon_{t}\left(a ; a^{\prime}\right)$ as in (2). On almost each path $\omega, \varepsilon_{t}\left(a ; a^{\prime}\right)$ is bounded.

\section{Proof of lemma 9}

Consider first the acts in $A^{\prime}$ as defined in the proof of lemma 8. Consider a period $t$ in which the decision-maker switches to an act $a \in A^{\prime}$ from a different act $a^{\prime} \in A^{\prime}$. Obviously, to satisfy the case-based rule:

$$
U_{t-1}\left(a^{\prime}\right) \geq U_{t-1}(a)
$$

and

$$
U_{t}(a) \geq U_{t}\left(a^{\prime}\right)
$$

must hold. Hence,

Now note, that starting from the interval

$$
U_{t}(a)-U_{t}\left(a^{\prime}\right) \in\left[0 ;\left(\bar{u}-\min _{u \in \Delta_{a^{\prime}}} u\right)\left(1-s\left(a ; a^{\prime}\right)\right)\right] .
$$

$$
\left[0 ;\left(\bar{u}-\min _{u \in \Delta_{a^{\prime}}} u\right)\left(1-s\left(a ; a^{\prime}\right)\right)\right],
$$

the difference between the cumulative utilities of $a$ and $a^{\prime}$ behaves as a random walk on a halfline with negative expected increments:

$$
\left[1-s\left(a ; a^{\prime}\right)\right]\left(\mu_{a}-\bar{u}\right)<0,
$$

as long as $a$ is chosen. Define $\tilde{\varepsilon}_{t}\left(a ; a^{\prime}\right)$ as

$$
\begin{aligned}
& \tilde{\varepsilon}_{t}\left(a ; a^{\prime}\right)=\varepsilon_{t}\left(a ; a^{\prime}\right) \text { if } \varepsilon_{t}\left(a ; a^{\prime}\right) \geq 0 \\
& \tilde{\varepsilon}_{t}\left(a ; a^{\prime}\right)=0, \text { else. }
\end{aligned}
$$

Such a random walk has an accessible atom at 0 (Meyn and Tweedie (1996, p. 105) give a definition of an accessible atom). Moreover, each set of the type $[0 ; c]$ is regular, see Meyn and Tweedie (1996, p. 278). This means that the state 0 is reached in finite expected time, starting from each set of the type $[0 ; c]$ and especially, starting from the set

$$
\left[0 ;\left(\bar{u}-\min _{u \in \Delta_{a^{\prime}}} u\right)\left(1-s\left(a ; a^{\prime}\right)\right)\right] .
$$

Denote the supremum of these expected times by $\mathcal{N}$ and observe that it is finite according to the definition of regular sets. Note that

$$
\bar{u}_{1}-\min _{u \in \Delta_{a^{\prime}}} u
$$


equals the supremum of $\varepsilon_{t}\left(a ; a^{\prime}\right)$ in a period, in which the decision-maker switches from an arbitrary $\tilde{a}$ to $a$. Observe as well that since the probability that $\varepsilon_{t}\left(a ; a^{\prime}\right)=0$ is 0 (for atomless distributions $\left.\Pi_{a}\right)$, it follows that $\tilde{\varepsilon}_{t}\left(a ; a^{\prime}\right)=0$ a.s. coincides with $\varepsilon_{t}\left(a ; a^{\prime}\right)<0$. Hence, the decision-maker switches away from $a$ when $\tilde{\varepsilon}_{t}\left(a ; a^{\prime}\right)=0$ is reached or in an earlier period. It follows that the expected time for which an arbitrary act $a$ is held in a row is finite and uniformly bounded from above.

It remains to show that $\varepsilon_{t}\left(a ; a^{\prime}\right)$ is bounded on almost each path of dividend realizations. At times at which $a$ is chosen $\varepsilon_{t}\left(a ; a^{\prime}\right)$ never falls below 0 , since this would contradict choosing the act with highest cumulative utility in each period. Suppose, therefore that there is a sequence of periods $t^{\prime}, t^{\prime \prime} \ldots$, such that $\varepsilon_{t^{\prime}}\left(a ; a^{\prime}\right)$, $\varepsilon_{t^{\prime \prime}}\left(a ; a^{\prime}\right) \ldots$ grows to infinity. In other words, suppose that for each $\mathcal{M}>0$ there is a $k$, such that $\varepsilon_{t^{n}}\left(a ; a^{\prime}\right)>\mathcal{M}$ for all $n>k$. It has been shown above that each other act in $A^{\prime}$ and especially $a^{\prime}$ is chosen infinitely many times on almost each path of dividend realizations. But each time that the act $a^{\prime}$ is chosen, the difference $\varepsilon_{t}\left(a ; a^{\prime}\right)$ falls below 0 . If $\varepsilon_{t^{n}}\left(a ; a^{\prime}\right)>\mathcal{M}$, the time needed to return to the origin is at least

$$
\frac{\mathcal{M}}{\left(1-s\left(a ; a^{\prime}\right)\right)\left[\bar{u}_{1}-\min _{u \in \Delta_{a}} u\right]},
$$

which grows to infinity, as $\varepsilon_{t^{n}}$ and, hence, $\mathcal{M}$ becomes very large. However, as has been explained above, the expected time for return to the origin 0 of $\tilde{\varepsilon}_{t}\left(a ; a^{\prime}\right)$ is finite and uniformly bounded above by $\mathcal{N}$. The Law of Large Numbers then implies that for each $\kappa>0$ on almost each path of dividend realizations there is a period $\mathcal{K}(\omega)$, such that

$$
\frac{\sum_{i=1}^{n} \tau_{i}}{n} \leq \mathcal{N}+\kappa
$$

for all $n \geq \mathcal{K}(\omega)$, where $\tau_{i}$ denotes the time needed for $\tilde{\varepsilon}_{t}\left(a ; a^{\prime}\right)$ to reach the origin, once $a$ has been chosen. On the other hand, the assumption that $\varepsilon_{t^{n}}\left(a ; a^{\prime}\right) \rightarrow \infty$ implies that the stopping times $\tau_{i}$ become infinitely large as the time grows - a contradiction. Hence, almost each sequence $\varepsilon_{t^{\prime}}\left(a ; a^{\prime}\right), \varepsilon_{t^{\prime \prime}}\left(a ; a^{\prime}\right) \ldots$ (where $t^{\prime}, t^{\prime \prime} \ldots$ denote periods at which $a$ is chosen) is bounded from above. A symmetric argument for $a^{\prime}$ shows that $\varepsilon_{t}\left(a ; a^{\prime}\right)$ is bounded from below. It follows that on almost each path $\omega \in \Omega$

holds for all acts $a, a^{\prime} \in A^{\prime}$.

$$
\lim _{t \rightarrow \infty} \frac{U_{t}(a)}{U_{t}\left(a^{\prime}\right)}=\lim _{t \rightarrow \infty} \frac{U_{t}(a)}{U_{t}(a)+\varepsilon_{t}\left(a ; a^{\prime}\right)}=1
$$

By lemma 8, there is no open subset of $A$ such that $A^{\prime}$ does not contain an act out of this interval, 
hence for each $\epsilon>0$, and $x \in \operatorname{int}(A)$, there is an $a \in A^{\prime} \cap B_{x}(\epsilon)$. Moreover, for all $\epsilon>0$,

$$
\lim _{t \rightarrow \infty} \frac{U_{t}(\tilde{a})}{U_{t}(a)}=1 \text {, }
$$

where $\tilde{a} \in A^{\prime} \cap B_{x}(\epsilon)$ and $a \in A^{\prime}, a \neq \tilde{a}$. Since

$$
\lim _{\epsilon \rightarrow 0} A^{\prime} \cap B_{x}(\epsilon)=x
$$

and $U_{t}(\tilde{a})$ is continuous in $\tilde{a}$, it follows that

$$
\lim _{t \rightarrow \infty} \frac{U_{t}(x)}{U_{t}(a)}=1,
$$

even if $x \notin A^{\prime}$. This completes the proof of the proposition.

\section{Proof of proposition 2}

The proof of proposition 1 has shown that if there is an open subset $\tilde{A} \subset[0 ; 1]$ such that

$$
\mu_{a}-\bar{u}>0
$$

for all $a \in \tilde{A}$, then the decision-maker will eventually choose an act out of this set. By continuity of $\mu_{a}$ with respect to $a$, if $\tilde{A}$ is not an open set, it must consist of a single corner act. By remark 1 , every corner act is also eventually chosen by the decision-maker. Moreover, by the proof of proposition 2, it cannot be that only acts outside $\tilde{A}$ are chosen infinitely often. This means that at least one act $a \in \tilde{A}$ will be chosen infinitely often. Suppose to the contrary of the statement of the proposition that there are two acts from $\tilde{A}, a$ and $a^{\prime}$, which are chosen with positive frequency. It is easy to show that this leads to a contradiction.

Indeed, consider the periods $z_{1 a}, z_{2 a}, \ldots \in \mathbb{N}$ at which the decision-maker switches to act $a$ and denote by $z_{1 a^{\prime}}, z_{2 a^{\prime}}, \ldots \in \mathbb{N}$ the times, at which the decision-maker switches to $a^{\prime}$. Then the proof of lemma 7 shows that:

$$
V_{z_{1 a}}(a)>V_{z_{1 a^{\prime}}}(a)=V_{z_{2 \alpha}}(a)>V_{z_{2 a^{\prime}}}(a)=V_{z_{3 a}}(a)>\ldots
$$

But these inequalities imply that $V_{t}(a)$, which is a random walk with positive expected increment $\mu_{a}-\bar{u}>0$, crosses each of the infinitely many boundaries $V_{z_{k a}}(a)$ from above. Since, however, there is a positive probability that a random walk with positive expected increment starting from a given point, never crosses a boundary lying below this point, see Grimmet and Stirzaker (1994, p. 144), and since the stopping times are independently distributed, it follows that the probability of infinitely many switches between $a$ and $a^{\prime}$ is 0 . Hence, only one of these two acts can be chosen with positive frequency in the limit.

Alternatively, suppose that an act $a^{\prime}$ from the set $A \backslash \tilde{A}$ is chosen infinitely often with an act from 
$\tilde{A}$. Then, with probability 1 , the cumulative utility of $a$ will become infinitely high, whereas the cumulative utility of $a^{\prime}$ will become infinitely low, as the number of periods grows to infinity. Hence, choosing act $a^{\prime}$ infinitely often will contradict the case-based decision rule, as well.

\section{Proof of proposition 4}

It has already been shown, see lemma 6 that for $\mu_{\bar{a}}-\bar{u}<0$, the investor switches in finite time to a corner act. Let $e^{i}$ be the first corner act chosen at some time $\bar{t}$, such that $\bar{t}=$ $\min \left\{t \mid U_{t}(\bar{a})<0\right\}$. Two cases are possible: either $\mu_{e^{i}}-\bar{u}<0$ or $\mu_{e^{i}}-\bar{u}>0$. Then at time $t>\bar{t}$ such that $a_{\tau}=e^{i}$ for all $\bar{t}<\tau \leq t$, the cumulative utility of an act $a$ can be written as:

$$
U_{t}(a)=V_{\bar{t}}(\bar{a}) s(a ; \bar{a})+V_{t}\left(e^{i}\right) s\left(a ; e^{i}\right) .
$$

As long as $V_{t}\left(e^{i}\right) \geq 0, e^{i}$ is chosen, according to lemma 7. If $\mu_{e^{i}}-\bar{u}>0$ holds, then $V_{t}\left(e^{i}\right)>0$ holds infinitely long in expectation. If, however, $\mu_{e^{i}}-\bar{u}<0$, then

$$
V_{t}\left(e^{i}\right)<\frac{V_{\bar{t}}(\bar{a})\left(s\left(e^{j} ; \bar{a}\right)-s\left(e^{i} ; \bar{a}\right)\right)}{1-s\left(e^{i} ; 1\right)}<0
$$

obtains in finite time for some $j \in\{1 \ldots K\}$. Let now $\bar{t}^{\prime}$ denote

$$
\bar{t}^{\prime}=\min \left\{t \mid V_{t}(0)<\frac{V_{\bar{t}}(\bar{a})\left(s\left(e^{j} ; \bar{a}\right)-s\left(e^{i} ; \bar{a}\right)\right)}{1-s(0 ; 1)} \text { for some } j \in\{1 \ldots K\}\right\} .
$$

Note that at $\bar{t}^{\prime}$ the cumulative utility of $a=e^{j}$ is:

$$
U_{\bar{t}^{\prime}}\left(e^{j}\right)=V_{\bar{t}}(\bar{a}) s\left(e^{j} ; \bar{a}\right) .
$$

Moreover, since now $V_{\bar{t}}(\bar{a})<0, V_{\bar{t}^{\prime}}(0)<0$ and $s$ is concave, it follows that at $\bar{t}^{\prime} U_{\bar{t}^{\prime}}(a)$ is convex for every $a \in A$. Therefore, the optimal act is a corner one. Now restrain $e^{j}$ to belong to the set:

Hence,

$$
\tilde{K}=\arg \max _{k \in\{1 \ldots K\} \backslash i}\left\{U_{\bar{t}^{\prime}}\left(e^{k}\right)\right\}
$$

$$
U_{\bar{t}^{\prime}}\left(e^{j}\right)=V_{\bar{t}}(\bar{a}) s\left(e^{j} ; \bar{a}\right)>V_{\bar{t}}(\bar{a}) s\left(e^{i} ; \bar{a}\right)+V_{\bar{t}^{\prime}}\left(e^{i}\right)=U_{\bar{t}^{\prime}}\left(e^{i}\right),
$$

so that one of the acts $e^{j}$ in set $\tilde{K}$ is chosen.

Again, if $\mu_{e^{j}}-\bar{u}>0$, then $a=e^{j}$ will be held infinitely long in expectation, whereas if $\mu_{e^{j}}-\bar{u}<0$, then the cumulative utility of $e^{j}$ becomes lower than the cumulative utility of any other corner act in finite time.

Lemma $10 a_{t} \in\left\{e^{k}\right\}_{k=1}^{K}$ for all $t>\bar{t}$. 


\section{Proof of lemma 10}

It has already been shown that the statement holds until period $\bar{t}^{\prime}$. To argue by induction, suppose that only corner acts have been chosen up to some time $t$. At time $t$, the cumulative utility of an act $a$ is given by:

$$
U_{t}(a)=V_{t}(\bar{a}) s(a ; \bar{a})+\sum_{k=1}^{K} V_{t}\left(e^{k}\right) s\left(e^{k} ; a\right) .
$$

Let $a_{t}=e^{l}$. As shown in lemma 7, if $V_{t}\left(e^{l}\right) \geq 0$, then $a_{t+1}=e^{l}$. If, however $V_{t}\left(e^{l}\right)<0$, then, by lemma $7, V_{t}\left(e^{k}\right) \leq 0$ holds for all $k=1 \ldots K$ with strict inequality for all corner acts selected at least once in the past. Since $s(\cdot ; \cdot)$ is a concave function, $U_{t}(a)$ becomes convex and has a corner maximum. Hence, $a_{t+1} \in\left\{e^{k}\right\}_{k=1}^{K}$.

Consider first the case of $\mu_{e^{k}}<\bar{u}$ for all $k \in\{1 \ldots K\}$.

Lemma 11 Each of the corner acts $e^{k}, k \in\{1 \ldots K\}$ satisfies $\lim _{t \rightarrow \infty}\left|C_{t}\left(e^{k}\right)\right|=\infty$.

\section{Proof of lemma 11}

Suppose that one of the corner acts is not chosen infinitely often. Let this be act $e^{k}$ Obviously, since the number of corner acts is finite, at least one of them must be chosen infinitely often. Let this be act $e^{j}$. Then, it follows that

$$
\lim _{t \rightarrow \infty} U_{t}\left(e^{j}\right)=\lim _{t \rightarrow \infty} V_{\bar{t}}(\bar{a}) s\left(e^{j} ; \bar{a}\right)+V_{t}\left(e^{j}\right)=-\infty,
$$

since $V_{\bar{t}}(\bar{a})$ is finite and $\mu_{e^{j}}-\bar{u}<0$, whereas $U_{t}\left(e^{k}\right)$ remains finite. Hence, a.s. there is a time $T(\omega)$ such that

$$
U_{t}\left(e^{j}\right)<U_{t}\left(e^{k}\right)
$$

for all $t>T(\omega)$ and still $a_{t}=e^{j}$ in some of the periods in contradiction to the case-based rule.

Now, consider the following process: let $k, l \in\{1 \ldots K\}, k \neq l$ and

$$
\begin{aligned}
& \varepsilon_{\bar{t}}\left(e^{k} ; e^{l}\right)= V_{\bar{t}}(\bar{a})\left[s\left(e^{k} ; \bar{a}\right)-s\left(e^{l} ; \bar{a}\right)\right] \\
& \varepsilon_{t+1}(1 ; 0)= \varepsilon_{t}+u_{t}\left(\delta_{t}^{k}\right)-\bar{u}, \quad \text { if } \varepsilon_{t} \geq 0 \\
& \varepsilon_{t}+u_{t}\left(\delta_{t}^{l}\right)-\bar{u}, \quad \text { if } \varepsilon_{t}<0
\end{aligned} .
$$

$\varepsilon_{t}\left(e^{k} ; e^{l}\right)$ represents the difference between the cumulative utilities of the acts $e^{k}$ and $e^{l}$ after period $\bar{t}$. To see this note that for $t \geq \bar{t}$,

$$
\begin{aligned}
& U_{t}\left(e^{k}\right)-U_{t}\left(e^{l}\right) \\
= & {\left[V_{t}\left(e^{k}\right)+V_{\bar{t}}(\bar{a}) s\left(e^{k} ; \bar{a}\right)\right]-\left[V_{t}\left(e^{l}\right)+V_{\bar{t}}(\bar{a}) s\left(e^{l} ; \bar{a}\right)\right]=}
\end{aligned}
$$




$$
\begin{aligned}
& =\left[V_{t}\left(e^{k}\right)-V_{t}\left(e^{l}\right)\right]+V_{\bar{t}}(\bar{a})\left[s\left(e^{k} ; \bar{a}\right)-s\left(e^{l} ; \bar{a}\right)\right]= \\
& =\varepsilon_{t}\left(e^{k} ; e^{l}\right) .
\end{aligned}
$$

An argument analogous to the one used to prove lemma 9 shows that $\varepsilon_{t}\left(e^{k} ; e^{l}\right)$ is bounded on almost each path $\omega$ and therefore:

with probability 1 . Hence,

$$
\lim _{t \rightarrow \infty} \frac{U_{t}\left(e^{k}\right)}{U_{t}\left(e^{l}\right)}=\lim _{t \rightarrow \infty} \frac{U_{t}\left(e^{l}\right)+\varepsilon_{t}\left(e^{k} ; e^{l}\right)}{U_{t}\left(e^{l}\right)}=1
$$

$$
\begin{aligned}
& \lim _{t \rightarrow \infty} \frac{\left[V_{t}\left(e^{k}\right)+V_{\bar{t}}(\bar{a}) s\left(e^{k} ; \bar{a}\right)\right]}{\left[V_{t}\left(e^{l}\right)+V_{\bar{t}}(\bar{a}) s\left(e^{l} ; \bar{a}\right)\right]}=1 \\
& \lim _{t \rightarrow \infty} \frac{\left[\left|C_{t}\left(e^{k}\right)\right| \sum_{\tau \in C_{t}\left(e^{k}\right)} \frac{\left[u_{\tau}-\bar{u}\right]}{\left|C_{t}\left(e^{k}\right)\right|}+V_{\bar{t}}(\bar{a}) s\left(e^{k} ; \bar{a}\right)\right]}{\left[\left|C_{t}\left(e^{l}\right)\right| \sum_{\tau \in C_{t}\left(e^{l}\right)} \frac{\left[u_{\tau}-\bar{u}\right]}{\left|C_{t}\left(e^{l}\right)\right|}+V_{\bar{t}}(\bar{a}) s\left(e^{l} ; \bar{a}\right)\right]}=1 .
\end{aligned}
$$

Since $\left|C_{t}\left(e^{k}\right)\right| \rightarrow \infty$ and $\left|C_{t}\left(e^{l}\right)\right| \rightarrow \infty$ on almost each path, it follows according to the Law of Large Numbers that

obtain almost surely in the limit. Hence,

$$
\begin{aligned}
& \lim _{t \rightarrow \infty} \frac{\sum_{\tau \in C_{t}\left(e^{k}\right)}\left[u_{\tau}-\bar{u}\right]}{\left|C_{t}\left(e^{k}\right)\right|}=\mu_{e^{k}}-\bar{u} \\
& \lim _{t \rightarrow \infty} \frac{\sum_{\tau \in C_{t}\left(e^{l}\right)}\left[u_{\tau}-\bar{u}\right]}{\left|C_{t}\left(e^{l}\right)\right|}=\mu_{e^{l}}-\bar{u}
\end{aligned}
$$

$$
\begin{aligned}
& \lim _{t \rightarrow \infty} \frac{\left[\left|C_{t}\left(e^{k}\right)\right|\left(\mu_{e^{k}}-\bar{u}\right)+V_{\bar{t}}(\bar{a}) s\left(e^{k} ; \bar{a}\right)\right]}{\left[\left|C_{t}\left(e^{l}\right)\right|\left(\mu_{e^{l}}-\bar{u}\right)+V_{\bar{t}}(\bar{a}) s\left(e^{l} ; \bar{a}\right)\right]}=1 . \\
& \lim _{t \rightarrow \infty} \frac{\left[\left|C_{t}\left(e^{k}\right)\right|\left(\mu_{e^{k}}-\bar{u}\right)+V_{\bar{t}}(\bar{a}) s\left(e^{k} ; \bar{a}\right)\right]}{\left[\left|C_{t}\left(e^{l}\right)\right|\left(\mu_{e^{l}}-\bar{u}\right)+V_{\bar{t}}(\bar{a}) s\left(e^{l} ; \bar{a}\right)\right]} \\
& =\lim _{t \rightarrow \infty} \frac{\left[\frac{\left|C_{t}\left(e^{k}\right)\right|}{\left|C_{t}\left(e^{l}\right)\right|}\left(\mu_{e^{k}}-\bar{u}\right)+\frac{V_{\bar{t}}(\bar{a}) s\left(e^{k} ; \bar{a}\right)}{\left|C_{t}\left(e^{l}\right)\right|}\right]}{\left[\left(\mu_{e^{l}}-\bar{u}\right)+\frac{V_{\bar{t}}(\bar{a}) s\left(e^{l} ; \bar{a}\right)}{\left|C_{t}\left(e^{l}\right)\right|}\right]}= \\
& =\lim _{t \rightarrow \infty} \frac{\frac{\left|C_{t}\left(e^{k}\right)\right|}{\left|C_{t}\left(e^{l}\right)\right|}\left(\mu_{e^{k}}-\bar{u}\right)}{\left(\mu_{e^{l}}-\bar{u}\right)}=1
\end{aligned}
$$

almost surely holds (since $V_{\bar{t}}(\bar{a})$ is finite on almost all paths, it does not influence the limit behavior). Therefore, the limit frequencies $\pi\left(e^{k}\right)$ and $\pi\left(e^{l}\right)$ satisfy

$$
\frac{\pi\left(e^{k}\right)}{\pi\left(e^{l}\right)}=\lim _{t \rightarrow \infty} \frac{\left|C_{t}\left(e^{k}\right)\right|}{\left|C_{t}\left(e^{l}\right)\right|}=\frac{\mu_{e^{l}}-\bar{u}}{\mu_{e^{k}}-\bar{u}} .
$$

If at least one of the mean utilities $\mu_{e^{k}}$ exceeds $\bar{u}$, then applying the argument of the proof of proposition 2 shows that one of the acts with $\mu_{e^{k}}>\bar{u}$ is chosen with frequency 1 in the limit. 


\section{References}

Billot, A., Gilboa, I., Schmeidler, D. (2004). ”Axiomatization of an Exponential Similarity Function”, University of Tel Aviv, mimeo. Blonski, M. (1999). ”Social Learning with CaseBased Decision”, Journal of Economic Behavior and Organization 38: 59-77.

Buschena, D. E., Zilberman, D. (1995). ”Performance of the Similarity Hypothesis Relative to Existing Models of Risky Choice”, Journal of Risk and Uncertainty 11: 233-263.

Buschena, D. E., Zilberman, D. (1999). ”Testing the Effects of Similarity on Risky Choice: Implications for Violations of Expected Utility”, Theory and Decision 46: 253-280.

Chateauneuf, A., Tallon, J. M. (2002). ”Diversification, Convex Preferences and Non-Empty Core in the Choquet Expected Utility Model”, Economic Theory 19: 509-523.

Dekel, E. (1989). ”Asset Demand without the Independence Axiom”, Econometrica 57: 163169.

Gayer, G. (2003). ”Perception of Probabilities in Situations of Risk. A Case Based Approach”, Tel Aviv University, mimeo.

Gilboa, I., Schmeidler, D. (1995). ”Case-Based Decision Theory”, Quarterly Journal of Economics 110: 605-639.

Gilboa, I., Schmeidler, D. (1996). ”Case-Based Optimization”, Games and Economic Behavior 15: $1-26$.

Gilboa, I., Schmeidler, D. (1997). ”Act Similarity in Case-Based Decision Theory”, Economic Theory 9: 47-61.

Gilboa, I., Schmeidler, D. (2001). A Theory of Case-Based Decisions, Cambridge University Press, Cambridge.

Grimmet, G. R., Stirzaker, D. R. (1994). Probability and Random Processes, Oxford University Press, Oxford.

Meyn, S. P., Tweedie, R. L. (1996). Markov Chains and Stochastic Stability, Springer Verlag, Berlin, Heidelberg.

Nehring, K., Puppe, C. (2002). ”A Theory of Diversity”, Econometrica 70: 1155-1198. 
Nehring, K., Puppe, C. (2003). ”Diversity and Dissimilarity in Lines and Hierarchies”, Mathematical Social Sciences 45: 167-183.

Zizzo, D. J. (2002). "Preliminary Experimental Results on the Similarity Function in $2 \times 2$ and $3 \times 3$ Games”, University of Oxford, mimeo. 


\begin{tabular}{|c|c|c|c|c|c|}
\hline Nr. & Author & Title & 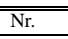 & Author & Title \\
\hline $04-43$ & $\begin{array}{l}\text { Fabian Bornhorst } \\
\text { Andrea Ichino } \\
\text { Oliver Kirchkamp } \\
\text { Karl H. Schlag } \\
\text { Eyal Winter }\end{array}$ & $\begin{array}{l}\text { How do People Play a Repeated Trust Game? } \\
\text { Experimental Evidence }\end{array}$ & $04-33$ & $\begin{array}{l}\text { Christopher Koch } \\
\text { Oliver Kirchkamp } \\
\text { J. Philipp Reiß }\end{array}$ & $\begin{array}{l}\text { Haftungserleichterungen bei der Offenlegung von } \\
\text { Zukunftsinformationen in den USA } \\
\text { The overbidding-myth and the underbidding-bias in } \\
\text { first-price auctions }\end{array}$ \\
\hline $04-42$ & Martin Hellwig & $\begin{array}{l}\text { Optimal Income Taxation, Public-Goods Provision } \\
\text { and Public-Sector Pricing: A Contribution to the } \\
\text { Foundations of Public Economics }\end{array}$ & $04-31$ & $\begin{array}{l}\text { Alexander Ludwig } \\
\text { Alexander Zimper }\end{array}$ & $\begin{array}{l}\text { Investment Behavior under Ambiguity: The Case of } \\
\text { Pessimistic Decision Makers }\end{array}$ \\
\hline $04-41$ & Thomas Gschwend & $\begin{array}{l}\text { Comparative Politics of Strategic Voting: A } \\
\text { Hierarchy of Electoral Systems }\end{array}$ & $04-30$ & Volker Stocké & $\begin{array}{l}\text { Attitudes Toward Surveys, Attitude Accessibility } \\
\text { and the Effect on Respondentsí Susceptibility to } \\
\text { Nonresponse }\end{array}$ \\
\hline $04-40$ & $\begin{array}{l}\text { Ron Johnston } \\
\text { Thomas Gschwend } \\
\text { Charles Pattie }\end{array}$ & On Estimates of Split-Ticket Voting: EI and EMax & 04-29 & Alexander Ludwig & $\begin{array}{l}\text { Improving Tatonnement Methods for Solving } \\
\text { Heterogeneous Agent Models }\end{array}$ \\
\hline $04-39$ & Volker Stocké & $\begin{array}{l}\text { Determinants and Consequences of Survey } \\
\text { Respondentsí Social Desirability Beliefs about }\end{array}$ & $04-28$ & $\begin{array}{l}\text { Marc Oliver Rieger } \\
\text { Mei Wang }\end{array}$ & $\begin{array}{l}\text { Cumulative Prospect Theory and the St.Petersburg } \\
\text { Paradox }\end{array}$ \\
\hline $04-38$ & $\begin{array}{l}\text { Siegfried K. Berninghaus } \\
\text { Marion Ott }\end{array}$ & $\begin{array}{l}\text { Racial Attitudes } \\
\text { Restricting the benefit flow from neighbors: } \\
\text { Experiments on network formation }\end{array}$ & $04-27$ & $\begin{array}{l}\text { Michele Bernasconi } \\
\text { Oliver Kirchkamp } \\
\text { Paolo Paruolo }\end{array}$ & $\begin{array}{l}\text { Do fiscal variables affect fiscal expectations? } \\
\text { Experiments with real world and lab data }\end{array}$ \\
\hline & Bodo Vogt & & $04-26$ & $\begin{array}{l}\text { Daniel Schunk } \\
\text { Cornelia Betsch }\end{array}$ & $\begin{array}{l}\text { Explaining heterogeneity in utility functions by } \\
\text { individual differences in preferred decision modes }\end{array}$ \\
\hline $04-37$ & Christopher Koch & $\begin{array}{l}\text { Behavioral Economics und die Unabhängigkeit des } \\
\text { Wirtschaftsprüfers - Ein Forschungsüberblick }\end{array}$ & $04-25$ & $\begin{array}{l}\text { Martin Weber } \\
\text { Jens Wuestemann }\end{array}$ & $\begin{array}{l}\text { Bedeutung des Börsenkurses im Rahmen der } \\
\text { Unternehmensbewertung }\end{array}$ \\
\hline $04-36$ & Christopher Koch & $\begin{array}{l}\text { Behavioral Economics und das } \\
\text { Entscheidungsverhalten des Wirtschaftsprüfers - } \\
\text { Ein Forschungsüberblick }\end{array}$ & $04-24$ & Hannah Hörisch & Does foreign aid delay stabilization \\
\hline $04-35$ & Christina Reifschneider & $\begin{array}{l}\text { Behavioral Law and Economics: Überlegungen zu } \\
\text { den Konsequenzen moderner Rationalitätskonzepte } \\
\text { für die Gestaltung informationellen }\end{array}$ & $04-23$ & $\begin{array}{l}\text { Daniel Schunk } \\
\text { Joachim Winter }\end{array}$ & $\begin{array}{l}\text { The Relationship Between Risk Attitudes and } \\
\text { Heuristics in Search Tasks: A Laboratory } \\
\text { Experiment }\end{array}$ \\
\hline & & Kapitalmarktrechts & $04-22$ & Martin Hellwig & $\begin{array}{l}\text { Risk Aversion in the Small and in the Large When } \\
\text { Outcomes Are Multidimensional }\end{array}$ \\
\hline $04-34$ & $\begin{array}{l}\text { Siegfried K. Berninghaus } \\
\text { Karl-Martin Ehrhart } \\
\text { Marion Ott } \\
\text { Bodo Vogt }\end{array}$ & $\begin{array}{l}\text { Searching for "Stars" - Recent Experimental } \\
\text { Results on Network Formation - }\end{array}$ & $04-21$ & $\begin{array}{l}\text { Oliver Kirchkamp } \\
\text { Eva Poen } \\
\text { J. Philipp Reiß }\end{array}$ & Bidding with Outside Options \\
\hline
\end{tabular}

SONDERFoRSCHUNGsBereich 504 WORKING PAPER SERIES

\begin{tabular}{|c|c|c|}
\hline Nr. & $\begin{array}{l}\text { Author } \\
\end{array}$ & "Title \\
\hline $04-20$ & Jens Wüstemann & $\begin{array}{l}\text { Evaluation and Response to Risk in International } \\
\text { Accounting and Audit Systems: Framework and } \\
\text { German Experiences }\end{array}$ \\
\hline 04-19 & Cornelia Betsch & $\begin{array}{l}\text { Präferenz für Intuition und Deliberation (PID): } \\
\text { Inventar zur Erfassung von affekt- und } \\
\text { kognitionsbasiertem Entscheiden }\end{array}$ \\
\hline $04-18$ & Alexander Zimper & Dominance-Solvable Lattice Games \\
\hline 04-17 & $\begin{array}{l}\text { Volker Stocké } \\
\text { Birgit Becker }\end{array}$ & $\begin{array}{l}\text { DETERMINANTEN UND KONSEQUENZEN } \\
\text { DER UMFRAGEEINSTELLUNG. } \\
\text { Bewertungsdimensionen unterschiedlicher } \\
\text { Umfragesponsoren und die Antwortbereitschaft der } \\
\text { Befragten }\end{array}$ \\
\hline $04-16$ & $\begin{array}{l}\text { Volker Stocké } \\
\text { Christian Hunkler }\end{array}$ & $\begin{array}{l}\text { Die angemessene Erfassung der Stärke und } \\
\text { Richtung von Anreizen durch soziale Erwünschtheit }\end{array}$ \\
\hline $04-15$ & $\begin{array}{l}\text { Elena Carletti } \\
\text { Vittoria Cerasi } \\
\text { Sonja Daltung }\end{array}$ & $\begin{array}{l}\text { Multiple-bank lending: diversification and } \\
\text { free-riding in monitoring }\end{array}$ \\
\hline 04-14 & Volker Stocké & $\begin{array}{l}\text { The Interdependence of Determinants for the } \\
\text { Strength and Direction of Social Desirability Bias } \\
\text { in Racial Attitude Surveys }\end{array}$ \\
\hline 04-13 & $\begin{array}{l}\text { Christopher Koch } \\
\text { Paul Fischbeck }\end{array}$ & $\begin{array}{l}\text { Evaluating Lotteries, Risks, and Risk-mitigation } \\
\text { Programs No A Comparison of China and the } \\
\text { United States }\end{array}$ \\
\hline 04-12 & $\begin{array}{l}\text { Alexander Ludwig } \\
\text { Torsten Sløk }\end{array}$ & $\begin{array}{l}\text { The relationship between stock prices, house prices } \\
\text { and consumption in OECD countries }\end{array}$ \\
\hline 04-11 & Jens Wüstemann & Disclosure Regimes and Corporate Governance \\
\hline 04-10 & $\begin{array}{l}\text { Peter Albrecht } \\
\text { Timo Klett }\end{array}$ & $\begin{array}{l}\text { Referenzpunktbezogene risikoadjustierte } \\
\text { Performancemaße: Theoretische Grundlagen }\end{array}$ \\
\hline 04-09 & Alexander Klos & $\begin{array}{l}\text { The Investment Horizon and Dynamic Asset } \\
\text { Allocation - Some Experimental Evidence }\end{array}$ \\
\hline
\end{tabular}

SONDERFORSCHUNGSBereich 504 WORKING PAPER SERIES

\begin{tabular}{|c|c|c|}
\hline$\overline{\mathrm{Nr} .}$ & $\begin{array}{l}\text { Author } \\
\end{array}$ & Title \\
\hline 04-08 & $\begin{array}{l}\text { Peter Albrecht } \\
\text { Cemil Kantar } \\
\text { Yanying Xiao }\end{array}$ & $\begin{array}{l}\text { Mean Reversion-Effekte auf dem deutschen } \\
\text { Aktienmarkt: Statistische Analysen der } \\
\text { Entwicklung des DAX-KGV }\end{array}$ \\
\hline 04-07 & Geschäftsstelle & Jahresbericht 2003 \\
\hline 04-06 & Oliver Kirchkamp & $\begin{array}{l}\text { Why are Stabilisations delayed - an experiment } \\
\text { with an application to all pay auctions }\end{array}$ \\
\hline 04-05 & $\begin{array}{l}\text { Karl-Martin Ehrhart } \\
\text { Marion Ott }\end{array}$ & Auctions, Information, and New Technologies \\
\hline 04-04 & Alexander Zimper & $\begin{array}{l}\text { On the Existence of Strategic Solutions for Games } \\
\text { with Security- and Potential Level Players }\end{array}$ \\
\hline 04-03 & Alexander Zimper & $\begin{array}{l}\text { A Note on the Equivalence of Rationalizability } \\
\text { Concepts in Generalized Nice Games }\end{array}$ \\
\hline 04-02 & Martin Hellwig & $\begin{array}{l}\text { The Provision and Pricing of Excludable Public } \\
\text { Goods: Ramsey-Boiteux Pricing versus Bundling }\end{array}$ \\
\hline 04-01 & $\begin{array}{l}\text { Alexander Klos } \\
\text { Martin Weber }\end{array}$ & $\begin{array}{l}\text { Portfolio Choice in the Presence of Nontradeable } \\
\text { Income: An Experimental Analysis }\end{array}$ \\
\hline 03-39 & $\begin{array}{l}\text { Eric Igou } \\
\text { Herbert Bless }\end{array}$ & $\begin{array}{l}\text { More Thought - More Framing Effects? Framing } \\
\text { Effects As a Function of Elaboration }\end{array}$ \\
\hline $03-38$ & $\begin{array}{l}\text { Siegfried K. Berninghaus } \\
\text { Werner Gueth } \\
\text { Annette Kirstein }\end{array}$ & $\begin{array}{l}\text { Trading Goods versus Sharing Money - An } \\
\text { Experiment Testing Wether Fairness and Efficiency } \\
\text { are Frame Dependent }\end{array}$ \\
\hline $03-37$ & $\begin{array}{l}\text { Franz Urban Pappi } \\
\text { Thomas Gschwend }\end{array}$ & $\begin{array}{l}\text { Partei- und Koalitionspräferenzen der Wähler bei } \\
\text { der Bundestagswahl } 1998 \text { und } 2002\end{array}$ \\
\hline $03-36$ & Martin Hellwig & $\begin{array}{l}\text { A Utilitarian Approach to the Provision and Pricing } \\
\text { of Excludable Public Goods }\end{array}$ \\
\hline $03-35$ & Daniel Schunk & $\begin{array}{l}\text { The Pennsylvania Reemployment Bonus } \\
\text { Experiments: How a survival model helps in the } \\
\text { analysis of the data }\end{array}$ \\
\hline
\end{tabular}

